\section{ANAEMIA IN THE ELDERLY} BY

\section{ADRIAN SEMMENCE, M.D., D.Obst.R.C.O.G. General Practitioner, Withernsea, Yorkshire}

The literature on haemoglobin levels in the elderly is conflicting and apparently varies with the population studied. Howell (1950) found high values and little anaemia in a group of elderly patients in a hospital for the chronic sick. Monroe (1951) found a much higher incidence of anaemia in patients over the age of 61 in a geriatric hospital. Hobson and Blackburn's (1953) survey of elderly people living alone or with spouse showed that $6.5 \%$ of women over the age of 60 and $5.1 \%$ of men over the age of 65 had haemoglobin levels below $80 \%$ Haldane. In the area in which I practise anaemia appears to be more common. The practice, of which I am junior partner, is a rural and semi-urban one, very widely scattered over about 120 square miles (310 square $\mathrm{km}$.). About half my patients live in a small seaside town of 5,000 inhabitants, and half in the surrounding countryside.

\section{Basis of the Survey}

Of a total of 275 patients who were aged 65 or over on August 18, 1956. 256 (101 men and 155 women) had blood samples taken. The estimations were made between July, 1955. and December, 1956. During this period eight patients (five men and three women) refused to have a blood sample taken, seven (five men and two women) died, and four (two men and two women) left the practice before estimations could be performed.

Haemoglobin was estimated by the M.R.C. grey wedge photometer (King et al., 1948) on oxalated venous blood. Other haematological estimations found necessary were carried out in the usual way. A level of $80 \%$ (Haldane haemoglobin standard, $100 \%=14.8 \mathrm{~g} . /$ $100 \mathrm{ml}$.) (King et al., 1947) or under was taken as pathological and the patients were investigated further.

Patients were grouped according to the RegistrarGeneral's classification (General Register Office, 1956), and a survey classification was also employed, based on the apparent material comfort of the persons concerned. Patients were also grouped into those living alone or not.

\section{Treatment of Anaemic Cases}

At first ferrous gluconate was used as the routine oral iron preparation, but ferrous sulphate was substituted later. There were no cases of intolerance of ferrous sulphate in the 10 patients with anaemia for whom it was prescribed. In this survey poor nutrition appeared to be a major factor in the female cases of anaemia, and supplements of ascorbic acid and vitaminB complex were prescribed for the majority of anaemic patients.

Three patients whose anaemia did not seem to respond to oral iron were treated with parenteral iron preparations.

The anaemia in four patients (three men and one woman) was taken to be irreversible (two had inoperable carcinoma, one had leukaemia, and the fourth had left the district before follow-up). Treatment of the other cases of anaemia produced a rise in haemoglobin, and to facilitate comparison with other surveys the results were calculated on two sets of values: (1) the uncorrected haemoglobin levels (the values obtained from the initial blood samples in the patients studied); and (2) the corrected haemoglobin levels (for these the irreversible cases of anaemia were excluded; the levels achieved after treatment of the " anaemic " cases-those where the haemoglobin was less than $80 \%$-and the original values for the non-anaemic cases were used).

\section{Results}

Anuemia

Five men (5\%) and 20 women (13\%) had haemoglobin levels below $80 \%$ (11.84 g. $/ 100 \mathrm{ml}$.). Anaemia in men is usually of serious significance (Brown, 1956), and this the survey confirmed. In two men the anaemia appeared to be due to carcinoma, in one to leukaemia, in one to Addisonian anaemia, and in one to a bleeding duodenal ulcer.

The incidence of anaemia in women $(13 \%)$ is much higher than that found in Hobson and Blackburn's (1953) survey $(5 \%)$. In 10 cases the anaemia appeared to be due to poor nutrition, in four to haemorrhage, in two to haemorrhage and poor nutrition, in one to haemorrhage and arthritis, in one to haemorrhage and carcinoma, and in one to Addisonian anaemia ; in one case the cause was unknown, the patient having left the district.

None of the female patients in whom poor nutrition was believed to play a major part in the production of their anaemia had any symptoms related to the gastrointestinal or genito-urinary tracts ; clinical examination was negative : all responded to oral iron, and one year later had not relapsed.

\section{Haemoglobin and Age}

The haemoglobin level in men gradually decreased with increasing age, though the rate of decrease was not constant. The mean (corrected) haemoglobin level of three unequal age groups was:

$$
\begin{aligned}
& \text { Age 65-70 years } \quad \ldots \quad 98.4 \%(14.5 \mathrm{~g} . / 100 \mathrm{ml} .) \\
& \begin{array}{llll}
\text { Age } 71-82 & \prime & \cdots & 95.7 \%(14.2 \mathrm{~g} . / 100 \mathrm{ml} .) \\
\text { Age } 83+ & " & . & 92.4 \%(13.8 \mathrm{~g} . / 100 \mathrm{ml} .)
\end{array}
\end{aligned}
$$

In women the haemoglobin level gradually increased with increasing age, though the rate of increase was not constant. The mean (corrected) haemoglobin level of the three unequal age groups was:

$$
\begin{array}{lllll}
\text { Age } 65-70 & \text { years } & \ldots & 91.0 \%(13.5 \mathrm{~g} . / 100 \mathrm{ml} .) \\
\text { Age } 71-82 & , & \ldots & 92.2 \%(13.6 \mathrm{~g} . / 100 \mathrm{ml} .) \\
\text { Age } 83+ & \# & \ldots & 94.3 \%(14.0 \mathrm{~g} . / 100 \mathrm{ml} .)
\end{array}
$$

At the age of 65 the mean (corrected) haemoglobin level in men was significantly higher than that in women, but with increasing age the level in men decreased, and in women increased, until at the age of 74 significant differences disappeared.

The gradual decrease in the haemoglobin of men with increasing age is widely accepted, and several workers have shown a gradual increase in that of women (Committee on Haemoglobin Surveys, 1945 ; Olbrich, 1947); though other surveys have shown a decrease in the women studied as well as in the men (Hobson and Blackburn, 1953 ; Walsh et al., 1953).

The disappearance of significant difference between the haemoglobin levels of men and women in extreme age has been established in other reports (Olbrich, 1947 ; Hawkins et al., 1954 ; Gillum and Morgan, 1955).

Haemoglobin and Sex

Mean haemoglobin levels for men and women were:

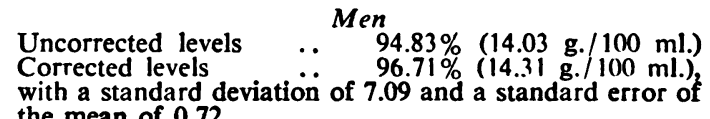
with a standard deviation of 7.09 and a standard error of the mean of 0.72 


Women
Uncorrected levels $\quad . \quad 89.44 \%(13.24 \mathrm{~g} . / 100 \mathrm{ml}$.)
Corrected levels
with a standard deviation of 7.07 and a standard error of
the mean of 0.57

For both the uncorrected and corrected values the means for men and women differ significantly at the 0.001 level of confidence.

There is considerable evidence that sex hormones play a part in the difference between the red-cell and haemoglobin level in lower male and female animals (Vollmer et al.. 1939 ; Domm et al., 1943 ; Finkelstein et al., 1944). Evidence in man, however, is conflicting (Widdowson and McCance, 1936; Vahlquist, 1950).

A hypothesis that a proportion of women are anaemic by the time of the menopause by reason of menstruation or repeated pregnancies, and that because of inadequate diet the iron-deficiency is not restored afterwards, would explain much of the data of this and other surveys. In this survey the differences in frequency of anaemia were significantly higher in women than in men $(\mathrm{P}<0.05)$. If an arbitrary level above the $80 \%$ Haldane used in this survey (say $90 \%$ ) had been chosen, and patients below this level investigated and treated, the difference in mean haemoglobin levels between men and women would, I think, have been narrowed further.

\section{Haemoglobin and Living Alone}

In this survey women living alone were found to have significantly lower haemoglobin levels than those not living alone. The mean uncorrected haemoglobin level for women living alone was $85.98 \%(12.73 \mathrm{~g} . / 100 \mathrm{ml}$.) and for women not living alone $90.90 \%$ (13.45 g./100 ml.). This difference was significant $(\mathrm{t}=2.66, \mathrm{P}<0.01)$.

Corrected haemoglobin levels, where the significant differences between the sexes in age, incidence of anaemia, and frequency of living alone were also taken into account, also showed a significant difference, the mean haemoglobin level for women living alone being $89.26 \%(13.21 \mathrm{~g} . / 100 \mathrm{ml}$.), and for women not living alone $92.64 \%$ (13.7 g. $/ 100 \mathrm{ml}$.) ; difference significant at 0.05 level $(\mathrm{t}=2.4, \mathrm{P}=0.02)$.

The mean (uncorrected) haemoglobin level for men living alone $(90.30 \%=13.3 \mathrm{~g} . / 100 \mathrm{ml}$.) was not quite significantly lower at the 0.05 level of confidence $(P$ approximately 0.10 ) than for men not living alone ( $95.33 \%=14.11$ g. $/ 100 \mathrm{ml}$.).

Corrected haemoglobin levels also showed no significant difference, the mean haemoglobin level for men living alone being $95.9 \%(14.19 \mathrm{~g} . / 100 \mathrm{ml}$.) and for men not living alone $93.3 \%(13.81 \mathrm{~g} . / 100 \mathrm{ml}$. $(\mathrm{t}=1.08, \mathrm{P}=0.30)$.

It is not likely that sex hormone factors could account for the significantly lower haemoglobin levels for women living alone compared with those not living alone. The clinical impression that women living alone are probably the section of the population who care least about proper feeding would do so.

\section{Haemoglobin and Social Class}

There was no significant difference in the incidence of anaemia in the various Registrar-General or survey classes, nor in the mean haemoglobin level of men and women in those classes (because of the small numbers involved Registrar-General classes I and II and IV and $\mathrm{V}$ were amalgamated for statistical analysis).

\section{Summary and Conclusions}

Haemoglobin estimations were performed on 101 men and 155 women over the age of 65 in a general practice.
At the age of 65 the haemoglobin levels were significantly higher in men than in women, but with increasing age the haemoglobin level of men gradually decreased, and that of women gradually increased, until at the age of 74 significant differences disappeared.

Five men $(5 \%)$ and 20 women $(13 \%)$ had haemoglobin levels below $80 \%$ Haldane (11.84 g./100 ml.).

There were no significant differences in haemoglobin levels in the various Registrar-General classes, nor in those of a classification based on apparent material comfort.

In this survey it appeared that a major factor in the high incidence of anaemia in women over the age of 65 was poor nutrition, and it is suggested that it may be a major factor in the difference in haemoglobin levels between the sexes in old age.

I am grateful to Dr. H. F. Barnard and the staff of the Pathology Laboratory, Westwood Hospital, Beverley, who made the haematological estimations, and to Mr. A. B. Royse, Hull University, for help with the statistics.

REFERENCES

Brown, A. (1956). Practitioner, 176, 434

Committee on Haemoglobin Surveys (1945). Spec. Rep. Ser. med.

Res. Coun. (Lond.), No. 252 .
Domm, L. V., Taber, E., and Davis, D. E. (1943). Proc. Soc. exp. Biol. (N.Y.), 52, 49 .

Finkelstein, G., Gordon, A. S., and Charipper, H. A. (1944). Endocrinology, 35, 267

General Register Óffice (1956). Census 1951: Classification of Occupations. H.M.S.O., London.

Gillum, H. L., and Morgan, A. F. (1955). J. Nutr., 55, 265.

Hawkins, W W., Speck, E., and Leonard, V. G. (1954). Blood, 9, 999.

Hobson, W., and Blackburn, E. K. (1953). Brit. med. J., 1, 647. Howell, T. H. (1950). Old Age, 2nd ed., p. 22. Lewis, London.

King, E. J., Wootton, I. D. P., Donaldson, R., Sisson, R. B., and Macfarlane, R. G. (1948). Lancet, 2, 971.

- Gilchrist, M., Wootton, I. D. P., Donaldson, R., Sisson, R. B., Macfarlane, R. G., Jope, H. M., O'Brien, J. R. P., Peterson, J. M., and Strangeways, D. H. (1947). Ibid., 2, 789.

Monroe, R. T. (1951). Diseases in Old Age, p. 262. Harvard Univ. Press, Cambridge, Mass.

Olbrich, O. (1947). Edinb. med. J.. 54, 306.

Vahlquist, B. (1950). Blood, 5, 874

Vollmer, E. P., Gordon, A. S., Levenstein, I., and Charipper, H. A. (1939). Endocrinology, 25, 970

Walsh, R. J., Arnold, B. J., Lancaster, H. O., Coote, M. A., and Cotter, H. (1953). A Study of Haemoglobin Values in New South Wales. National Health and Med. Res. Coun. Spec. Rep. Ser., No. 5. Canberra.

Widdowson, E. M., and McCance, R. A. (1936). J. Hyg. (Lond.), 36, 13 .

\section{Medical Memoranda}

\section{Congenital Absence of Gall-bladder Asso- ciated with a High Caecum and Absence of Ascending Colon}

The following unusual case is thought to be of sufficient interest to be put on record.

\section{CASE Report}

A man aged 45 was first seen in the out-patient department on November 16, 1956, complaining of upper abdominal pain on the right side with some intolerance to fatty food, and flatulence. He was very tender over the gallbladder and to a lesser degree over the appendix area. Cholecystograms showed no function of the gall-bladder. Examination with the double-dose technique again showed no function of the gall-bladder. The radiologist reported the case as one of gall-bladder disease obliterating the cystic duct.

On admission the patient complained of right-sided abdominal pain of a sharp, gripping character, on and off for 